\title{
UM OLHAR SOBRE A CAMPANHA PUBLICITÁRIA GENTE BOA TAMBÉM MATA A PARTIR DE UM ENFOQUE SÓCIO DISCURSIVO
}

\author{
Graziela Hoerbe Andrighetti \\ Maíra da Silva Gomes
}

Submetido em 01 de junho de 2018.

Aceito para publicação em 18 de setembro de 2018.

Cadernos do IL, Porto Alegre, n. ${ }^{\circ}$ 56, mês de novembro. p. 24-37

\section{POLÍTICA DE DIREITO AUTORAL}

Autores que publicam nesta revista concordam com os seguintes termos:

(a) Os autores mantêm os direitos autorais e concedem à revista o direito de primeira publicação, com o trabalho simultaneamente licenciado sob a Creative Commons Attribution License, permitindo o compartilhamento do trabalho com reconhecimento da autoria do trabalho e publicação inicial nesta revista.

(b) Os autores têm autorização para assumir contratos adicionais separadamente, para distribuição não exclusiva da versão do trabalho publicada nesta revista (ex.: publicar em repositório institucional ou como capítulo de livro), com reconhecimento de autoria e publicação inicial nesta revista.

(c) Os autores têm permissão e são estimulados a publicar e distribuir seu trabalho online (ex.: em repositórios institucionais ou na sua página pessoal) a qualquer ponto antes ou durante o processo editorial, já que isso pode gerar alterações produtivas, bem como aumentar o impacto e a citação do trabalho publicado.

(d) Os autores estão conscientes de que a revista não se responsabiliza pela solicitação ou pelo pagamento de direitos autorais referentes às imagens incorporadas ao artigo. A obtenção de autorização para a publicação de imagens, de autoria do próprio autor do artigo ou de terceiros, é de responsabilidade do autor. Por esta razão, para todos os artigos que contenham imagens, o autor deve ter uma autorização do uso da imagem, sem qualquer ônus financeiro para os Cadernos do IL.

\section{POLÍTICA DE ACESSO LIVRE}

Esta revista oferece acesso livre imediato ao seu conteúdo, seguindo o princípio de que disponibilizar gratuitamente o conhecimento científico ao público proporciona sua democratização. 


\title{
UM OLHAR SOBRE A CAMPANHA PUBLICITÁRIA GENTE BOA TAMBÉM MATA A PARTIR DE UM ENFOQUE SÓCIO DISCURSIVO
}

\author{
AN ANALYSIS OF THE PUBLIC SAFETY CAMPAIN \\ GENTE BOA TAMBÉM MATA (GOOD PEOPLE KILL, \\ TOO) FROM A SOCIO-DISCURSIVE PERSPECTIVE
}

\author{
Graziela Hoerbe Andrighetti ${ }^{1}$ \\ Maíra da Silva Gomes ${ }^{* *}$
}

\begin{abstract}
RESUMO:
Partindo do pressuposto de que a linguagem é dialógica e situada na interação entre falantes, nos propomos a analisar neste artigo a polêmica campanha publicitária "Gente boa também mata”, lançada em 2016 pelo Ministério dos Transportes, Portos e Aviação, com o intuito de refletir sobre os diversos entendimentos envolvendo a campanha e sobre as relações entre o projeto enunciativo do enunciador e as interpretações ativas feitas pelos interlocutores. Para tanto, trazemos para a discussão uma das peças que compõem a campanha, bem como seus desdobramentos: comentários postados em redes sociais, trecho de reportagem de jornal e meme-resposta. Buscamos poder contribuir para as discussões envolvendo mídia e formação de leitores mais críticos.
\end{abstract}

PALAVRAS-CHAVE: campanha publicitária; discurso; dialogismo.

\begin{abstract}
:
Based on a socially situated perspective of language, this paper analyzes the controversial public safety campaign "Gente boa também mata" ("Good people kill, too"), launched in 2016 by the Brazilian government. Through a Bakhtinian perspective, we reflect on the relationship established between the enunciative purpose of the campaign and the understandings that emerged in responses in social network postings, newspaper articles, and memes that circulated on the web. The meanings involved in a communication event are situated, and depend on the context in which they occur. We seek to contribute to discussions involving media and the fostering of critical reading.
\end{abstract}

KEYWORDS: advertising campaigns; speech; dialogism.

\footnotetext{
${ }^{1}$ Professora do curso de Letras da UNISINOS, Mestre em Linguística Aplicada pela Universidade Federal do Rio Grande do Sul e bolsista CAPES-PROEX de doutorado em Linguística no Programa de Pós-graduação em Letras, Escola de Humanidades, PUCRS.

"* Professora do Instituto Federal do Rio Grande do Sul, Mestre em Linguística Aplicada pela Universidade Federal do Rio Grande do Sul e bolsista CAPES- PROEX de doutorado em Linguística no Programa de Pósgraduação em Letras, Escola de Humanidades, PUCRS.
} 


\section{Introdução}

Os anúncios publicitários são gêneros de grande circulação na mídia e, por sua abrangência, alcançam um público diverso de leitores. Por estarem presentes no dia a dia das pessoas, são responsáveis por formar opiniões e, muitas vezes, acabam por reproduzir discursos e reforçar estereótipos e padrões comportamentais. A análise de campanhas publicitárias representa oportunidades de refletir criticamente sobre o dialogismo da linguagem, sobre os discursos mobilizados, sobre as ideologias presentes e sobre como se dá a construção de sentidos. Nesse contexto, o objetivo deste artigo é trazer reflexões sobre as relações dialógicas estabelecidas a partir da campanha "Gente Boa também mata".

Essa campanha publicitária, de responsabilidade do Ministério dos Transportes, Portos e Aviação Civil, em parceria com uma agência publicitária privada e com a Secretaria de Comunicação Social (SECOM), causou polêmica na Internet desde o seu lançamento, em dezembro de 2016. Ela fez parte da Operação Rodovia e foi veiculada através de outdoors, cartazes e vídeos que circularam em paradas de ônibus, na televisão e em redes sociais na internet. Ao utilizar imagens que remetem a boas práticas de cidadania, seguidas de slogans - "Quem resgata animais na rua pode matar", "O melhor aluno da sala pode matar" - e frases de alerta - "Obedeça aos limites de velocidade", "Não use celular ao volante", a campanha tinha como objetivo, segundo declarações dadas pelo Ministério dos Transportes, chamar atenção da população em geral para cinco atitudes fatais ao volante: dirigir utilizando o celular e/ ou embriagado, andar em excesso de velocidade, fazer ultrapassagens irregulares e não utilizar cinto de segurança.

A campanha teve uma repercussão polêmica em redes sociais e em matérias publicadas na imprensa, suscitando discussões acerca das múltiplas interpretações geradas por suas peças publicitárias. Houve leitores que demonstraram indignação por considerarem falha a avaliação moral das pessoas representadas pelas imagens, misturando assuntos que envolvem boas práticas sociais, imprudências no trânsito e morte; leitores que enquadraram a campanha como de "mau gosto" por abordar de forma reducionista os assuntos envolvendo imprudências no trânsito e ações de cidadania; leitores que se sentiram ofendidos por se identificarem com as causas sociais utilizadas nas imagens (simpatizantes da causa animal, estudantes, voluntários em trabalhos sociais etc.), dentre outros entendimentos. Segundo declarações dadas pelo Governo à imprensa ${ }^{2}$, as frases utilizadas nas peças da campanha tinham a intenção de destacar atitudes que até mesmo "pessoas comuns", e principalmente envolvidas em boas práticas de cidadania, podem ter ao volante, mesmo que de forma involuntária. Segundo o Ministério, as peças buscavam passar a

\footnotetext{
${ }^{2}$ https://noticias.uol.com.br/cotidiano/ultimas-noticias/gente-boa-tambem-mata-campanha-de-transito-gerapolemica-na-internet.htm e http://veja.abril.com.br/entretenimento/conar-governo-deve-mudar-campanhagente-boa-tambem-mata/ acesso em 01/03/2017
} 
mensagem de que de nada adianta ser uma boa pessoa e praticar atos de solidariedade se há desrespeito às leis de trânsito.

A repercussão negativa da campanha "Gente boa também mata" culminou em denúncia de algumas de suas peças publicitárias ao CONAR (Conselho Nacional de Autorregulamentação Publicitária) e teve processo aberto no mesmo órgão em janeiro de 2017. O Conselho decidiu pela reprovação de algumas peças, entendendo-as como um ato de desrespeito à imagem dos cidadãos que praticam boas ações de cidadania.

Buscando refletir sobre a interlocução que se estabelece entre o propósito enunciativo da campanha e os entendimentos que surgem nas respostas dadas a ela em postagens de rede social, reportagens publicadas em jornais e memes que circularam na internet, nos propomos a analisar neste artigo a campanha "Gente boa também mata" sob uma perspectiva bakhtiniana do discurso. Para isso, selecionamos uma das peças publicitárias da campanha - outdoor "Quem resgata animais de rua pode matar", veiculado em paradas de ônibus - ; um trecho retirado de uma matéria jornalística repercutindo a campanha; duas postagens de redes sociais sobre a campanha (optamos por comentários que traziam críticas negativas à campanha por serem representativos da repercussão negativa que a campanha teve na mídia e na Internet) e um meme produzido em resposta à peça publicitária outdoor "Quem resgata animais de rua pode matar". Com a análise da interlocução estabelecida entre as peças publicitárias e as respostas a elas, pretendemos mostrar as relações dialógicas que se constroem no uso situado da linguagem, tanto na ativa compreensão responsiva dos interlocutores, como no cruzamento de discursos que são mobilizados no momento na enunciação.

Nas seções seguintes, apresentamos uma retomada dos principais conceitos da teoria do Círculo de Bakhtin, seguida de uma análise dos dados utilizados neste artigo à luz de tais teorias. Acrescentamos, ainda, algumas considerações finais.

\section{Negociando sentidos}

Segundo Bakhtin (2016), ao usarmos a língua para nos comunicarmos em qualquer campo da comunicação, o fazemos em forma de enunciados (orais e escritos), concretos e únicos, sempre de forma situada, levando-se em conta quem os profere, os propósitos estabelecidos e o público com o qual se fala ou se pretende falar. Segundo o autor, aprendemos conjuntamente a moldar nossos enunciados a partir das restrições impostas na situação de interação verbal.

Falamos apenas através de certos gêneros do discurso, isto é, todos os nossos enunciados têm formas relativamente estáveis e típicas de construção do conjunto. Dispomos de um rico repertório de gêneros do discurso orais e escritos. Em termos práticos, nós os empregamos de forma segura e habilidosa, mas em termos teóricos, podemos desconhecer inteiramente a sua existência (BAKHTIN 2016, p.38)

Moldamos esse nosso dizer levando em conta a situação de comunicação na qual nos encontramos, a posição que ocupamos como enunciadores, a posição ocupada por 
nossos interlocutores, a composição social das relações entre nós (interlocutores e enunciadores), bem como os propósitos que estabelecemos para essa enunciação. As escolhas que fazemos, e que constituem nossos enunciados, são uma totalidade de elementos: conteúdo temático, estilo de linguagem (seleção de recursos lexicais e gramaticais) e construção composicional - todos indissociavelmente relacionados e determinados pelo contexto específico do campo da comunicação no qual nos encontramos ao enunciarmos. Os gêneros do discurso são infinitos e vão sendo historicamente construídos na interação e na negociação permanente de sentidos entre os participantes de uma dada situação de comunicação. Ao interagirmos, atualizamos os gêneros discursivos, e criamos em nossas "relações sentidos diferentes - inclusive para um mesmo discurso, um mesmo enunciado, uma mesma palavra" (SOBRAL 2010, p.91).

$\mathrm{Na}$ interação, cada palavra, cada oração só pode ser compreendida a partir de um contexto específico de uso - o enunciado - e, portanto, respondida a partir de uma posição responsiva emoldurada nesse contexto. Fora de um contexto determinado, com interlocutores específicos, propósitos enunciativos e situação comunicativa, a língua não passa de pura abstração. Nesse sentido,

\begin{abstract}
a verdadeira substância da língua não é constituída por um sistema abstrato de formas linguísticas (língua como sistema de formas - objetivismo abstrato) nem pela enunciação monológica isolada (língua como expressão de uma consciência individual - subjetivismo idealista), nem pelo ato psicofisiológico de sua produção (atividade mental), mas pelo fenômeno social da interação verbal, realizada pela enunciação (enunciado) ou pelas enunciações (enunciados). A interação verbal constitui assim a realidade fundamental da língua (BAKHTIN/ VOLOSHINOV 2006, p.123)
\end{abstract}

As palavras, por si só, não têm valor; elas adquirem um aspecto expressivo somente no enunciado concreto. $\mathrm{O}$ que faz de uma palavra ou de uma oração um enunciado é algo maior do que as formas da língua, e está relacionado à intencionalidade do autor, ao seu projeto enunciativo e também à interpretação ativa na resposta do interlocutor. A interpretação responsiva é essencial para que o discurso se constitua, pois é na resposta do outro que um dado discurso se enriquece recebendo apoio ou objeção. Nas palavras de Sobral (2010, p.55), "a interpretação e a resposta estão dialeticamente fundidas e se condicionam mutuamente: uma é impossível sem a outra”. Ou seja, nessa concepção não há compreensão passiva, pois o ouvinte não está em uma posição inferior em relação ao falante. Segundo Bakhtin, "Toda compreensão da fala viva, do enunciado vivo é de natureza ativamente responsiva; toda compreensão é prenhe de resposta, e nessa ou naquela forma a gera obrigatoriamente: o ouvinte se torna falante" (BAKHTIN 2003, p. 25). Os dois - falante e ouvinte - constroem conjuntamente o enunciado, já que é para o outro que o enunciado é constituído: "na palavra me dou forma a mim mesmo do ponto de vista do outro (...) do ponto de vista de minha comunidade" (VOLOSHINOV 2010, p. 299). Assim, "Cada gênero do discurso, em cada campo da comunicação discursiva tem sua concepção típica de destinatário que o determina como gênero" (BAKHTIN, 2003, p. 63). Ao comunicar, o falante leva em consideração seu interlocutor, sua opinião, seu lugar social, seu grau de proximidade para produzir o seu enunciado e escolher o gênero e, ao mesmo tempo, reelabora e reorganiza seu dizer, dependendo da ativa responsividade do ouvinte. 
Ao construir o meu enunciado, procuro defini-lo de maneira ativa; por outro lado, procuro antecipá-lo, e essa resposta antecipável exerce, por sua vez, uma ativa influência sobre o meu enunciado (dou resposta pronta às objeções que prevejo, apelo para toda a sorte de subterfúgios, etc). Ao falar, sempre levo em conta o campo aperceptivo da percepção do meu discurso pelo destinatário: até que ponto ele está a par da situação, dispõe de conhecimentos especiais de um dado campo cultural da comunicação; levo em conta as suas concepções e convicções, os seus preconceitos, as suas simpatias e antipatias. Essa consideração irá determinar também a escolha do gênero do enunciado e a escolha dos procedimentos composicionais e, por último, dos meios linguísticos, isto é, o estilo do enunciado. (BAKHTIN 2003, p. 63 e 64)

Toda enunciação está permeada por um tom valorativo advindo da seleção verbal e extraverbal feita por quem a profere - "esses juízos e valorações se referem a uma certa totalidade na qual a palavra diretamente entra em contato com o acontecimento da vida e se funde com ele em uma unidade indissolúvel (BAKHTIN, 2011 p.155). Tal seleção tem como base o contexto de vida, a posição e os discursos que constituem o enunciador como sujeito. Além disso, dado que a enunciação só faz sentido nas relações dela com o outro, a seleção feita pelo enunciador também leva em conta o fato de ser endereçada a alguém e, ao trazer esse alguém para a conversa, também está implicada no tom valorativo de um enunciado, sendo o interlocutor, então, um parceiro da produção de sentido.

\section{O dialogismo e a construção conjunta de sentido}

"Tudo pode estar completamente redondo, mas uma frase fora do lugar ou com interpretação dúbia pode colocar tudo a perder e gerar uma série de questionamentos"”3. Esse enunciado faz parte de uma matéria, publicada em um jornal virtual, sobre a campanha "Gente boa também mata" e é um bom ponto de partida para iniciarmos nossa reflexão acerca do uso situado da linguagem.

Segundo Bakhtin (2016), nossa comunicação se dá em forma de enunciados concretos e únicos, a partir de um determinado campo de atividade humana. Nossos enunciados orais e escritos têm formas relativamente estáveis e típicas de construção - os gêneros discursivos - que organizam nossa comunicação e são estabelecidos historicamente. Ao enunciarmos, o fazemos de algum lugar (quem somos, que posição ocupamos), estabelecendo propósitos determinados e sempre nos direcionando a um ou mais interlocutores. Nesse sentido, “todo o discurso é 'endereçado', dirige-se a alguém e, portanto, traz esse alguém para a superfície” (SOBRAL, 2010 p.64).

Considerando que o dialogismo é constitutivo da linguagem, é preciso pensar que a enunciação se completa na interação social, com o outro, na resposta do outro a um determinado enunciado: "Cada discurso é dialógico, orientado a outra pessoa e a sua

3 Trecho retirado da reportagem "Gente boa também mata ganha memes na web", postada no website ADNEWS em 04 de janeiro de 2017, às 9h50. http://adnews.com.br/internet/gente-boa-tambem-mata-ganhamemes-na-web.html. Acesso em 01 de junho de 2018, às 09h08min. 
compreensão e a sua efetiva ou potencial resposta" (VOLOSHINOV, 1993/1930, p. 256, grifos do autor). Os enunciados são dialógicos não só por serem sempre direcionados a um interlocutor, mas também por serem relacionados a outros enunciados e a outros discursos, pois, conforme Bakhtin,

Cada enunciado é um elo na corrente complexamente organizada de outros enunciados (...) todo falante é por si mesmo um respondente em maior ou menor grau; porque ele não é o primeiro falante, o primeiro a ter violado o eterno silêncio do universo, e pressupõe a existência de alguns enunciados antecedentesdos seus e alheios - com os quais o seu enunciado dialoga (baseia-se neles, polemiza com eles, ou simplesmente os pressupõe já conhecidos do ouvinte) (BAKHTIN 2003, p. 26).

É preciso levar em conta o interlocutor e saber que suas interpretações acerca de um dado enunciado serão feitas também de forma situada, a partir de suas posições, de suas vivências e do contexto específico da enunciação. Nas palavras de Bakthin (2015):

esse meio heterodiscursivo de palavras do outro é dado ao falante não pelo objeto, mas na alma do ouvinte como seu campo aperceptivo, prenhe de resposta e objeções. Também para esse campo aperceptivo - não linguístico, mas concreto-expressivo - direciona-se todo enunciado. Dá-se um novo encontro do enunciado com a palavra do outro, que exerce uma nova influência original sobre o seu estilo. (BAKHTIN, 2015, p. 54)

Sob esse viés, e retomando o trecho mencionado acima, retirado da reportagem de um jornal virtual sobre a repercussão da campanha "Gente boa também mata", não podemos pensar que "tudo pode estar completamente redondo" ao enunciarmos, desconsiderando as possibilidades diversas de interpretações de nosso enunciado que surgem apenas, e somente apenas, na relação que se estabelece com o interlocutor. Sabemos, mesmo que de forma inconsciente, que essa relação dialógica está permeada por riscos e que os significados que dela emergem serão permanentemente negociados (SOBRAL, 2010). Em outras palavras, é um equívoco pensar que exista um enunciado "redondo" sem que a relação dele com o interlocutor seja levada em conta, assim como pensar que palavras e frases sejam capazes de "colocar tudo a perder" por si só.

Embora possamos compreender o significado linguístico de uma palavra isoladamente, precisamos conhecer o contexto específico que a envolve em uma situação de comunicação para poder ter uma posição responsiva em relação a ela. Nesse caso, nunca será a palavra isolada, e sim, a palavra emoldurada e delimitada pela alternância dos sujeitos do discurso, refletindo a realidade extra verbal que a envolve (BAKHTIN, 2016, p.45). Será, portanto, um enunciado e não apenas uma palavra, que na sua relação com seu leitor/ouvinte será passível de resposta. De acordo com Bakhtin (2016), as palavras não possuem valor por si sós. O juízo de valor e o aspecto expressivo são dados a elas unicamente no enunciado concreto. É a partir dele que a seleção das palavras adquire uma orientação "na direção do ouvinte por parte do autor, e a recepção dessa seleção advêm do contexto da vida, que impregna as palavras de julgamentos de valor, impondo, pois, ao seu significado uma direção específica" (SOBRAL, 2010 p.63 e 64).

Esse dialogismo, fundamental para se pensar o uso da linguagem, é um ponto 
crucial para discutirmos o projeto enunciativo da campanha "Gente boa também mata" e compreendermos seus desdobramentos. Todo discurso tem uma orientação dialógica, pois "em todas as suas vias no sentido do objeto, em todas as orientações, o discurso depara com a palavra do outro e não pode deixar de entrar numa interação viva e tensa com ele" (BAKHTIN, 2015 p.51). Nos distanciamos, pois, do enunciado mencionado no início desta seção, retirado de uma matéria jornalística. Embora ele seja uma tentativa de explicar as razões que levaram às polêmicas interpretações das peças da campanha "Gente boa também mata", apresenta uma posição reducionista do objeto ao desconsiderar que as interpretações acerca dele só podem surgir da relação entre o objeto, o enunciador e o interlocutor. Na seção seguinte, discorremos sobre a campanha "Gente boa também mata" e sobre seus desdobramentos sob uma perspectiva bakhtiniana de uso da linguagem.

\section{Gente boa também mata}

Segundo as declarações dadas pelo Ministério dos Transportes à mídia, o objetivo principal da campanha era chamar a atenção da população em geral para atitudes fatais ao volante, como dirigir utilizando o aparelho celular. No caso da peça publicitária com o slogan "Quem resgata animais na rua pode matar", a intenção, ainda segundo declarações do Ministério, seria a de destacar que mesmo pessoas com boas atitudes, a exemplo do que as imagens da peça mostram (pessoas envolvidas em causas em favor de animais etc.) podem cometer infrações de trânsito fatais. Entretanto, a campanha sofreu muitas críticas, tendo a proibição da circulação de algumas de suas peças decretada pelo Conselho Nacional de Auto-regulamentação Publicitária (CONAR).

A peça publicitária analisada neste artigo - um outdoor com o enunciado "Quem resgata animais na rua pode matar", veiculado em paradas de ônibus - está entre as que foram retiradas de circulação após julgamento realizado pelo CONAR. Como analisar as relações que se estabelecem entre o objetivo da campanha, segundo o Ministério, e a sua recepção polêmica por parte dos leitores? Vamos a algumas considerações. 


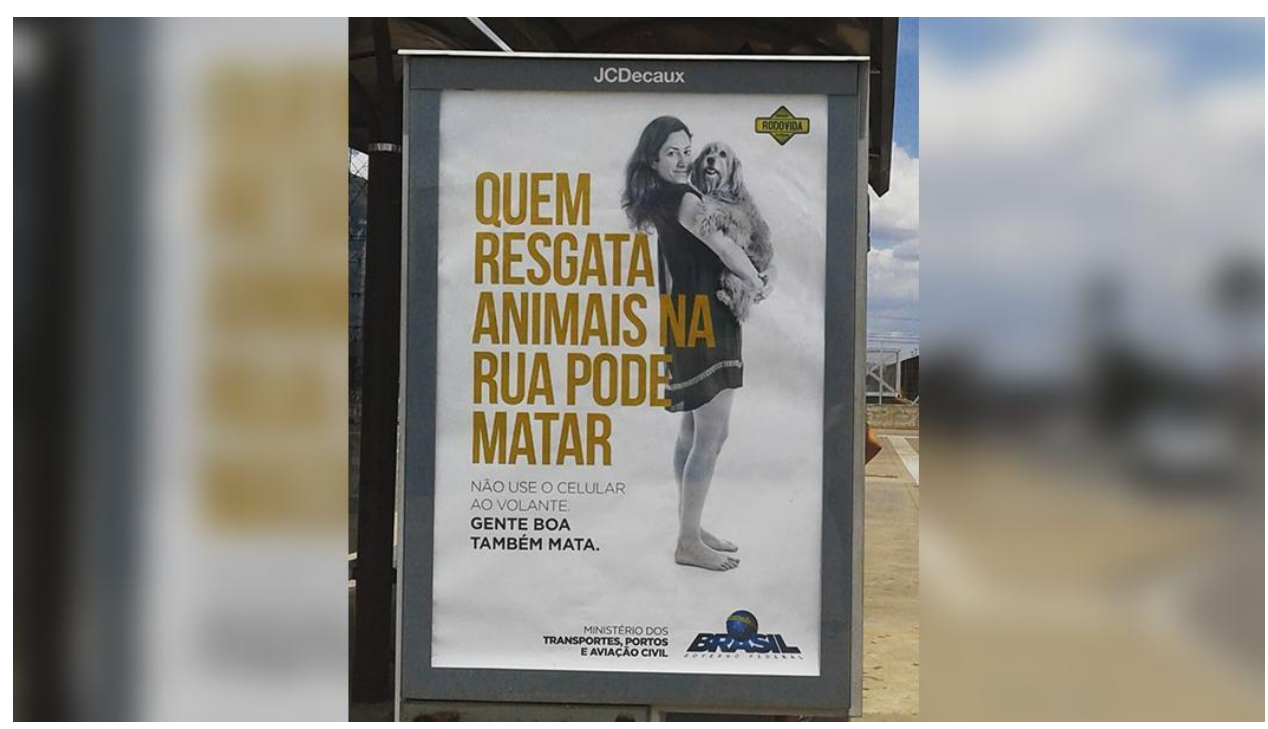

Figura 2- Peça publicitária "Quem resgata animais na rua pode matar"

Ao observarmos a forma composicional presente nesta peça publicitária, encontramos o contexto verbal composto pelo slogan "Quem resgata animais na rua pode matar" e um enunciado visual composto pela imagem de uma mulher sorrindo, segurando carinhosamente um cachorro no colo, que ocupam posição de destaque no conjunto do enunciado. Abaixo do slogan, dois enunciados em tamanho menor: a primeira delas, no imperativo, remete a uma regra de trânsito relacionada à proibição do uso de aparelho celular ao volante. A segunda, uma frase afirmativa, retoma o nome da campanha lançada pelo Ministério dos Transportes: "Gente boa também mata". A peça também apresenta, em sua parte inferior, a identificação do Ministério dos Transporte, Portos e Aviação Civil e do Governo Federal.

Todavia, a forma composicional é apenas um dos elementos a ser considerado em nossa análise. Precisamos ter em conta o contexto extra verbal que a compõe. Para Bakhtin (2011, p.154), a palavra não pode ser observada em si mesma. Ela "surge da situação extra verbal da vida e conserva com ela o vínculo mais estreito. E mais, a vida completa diretamente a palavra, a que não pode ser separada da vida sem que perca seu sentido" (BAKHTIN, 2011, p.154). A palavra está fundida aos acontecimentos da vida, ficando atrelado a essa fusão qualquer juízo de valor que possa ser feito sobre ela. A figura de uma mulher jovem segurando um cachorro no colo e sorrindo remete a um horizonte extra verbal positivo, traz para a peça um elemento importante que, somado à forma composicional, possibilita ao interlocutor interpretações e valorações acerca do enunciado.

Conforme exposto na seção anterior, para refletir sobre a campanha, é preciso olhar para as relações que vão sendo estabelecidas entre os interlocutores (leitores da campanha), o objeto (a peça publicitária outdoor "Quem resgata animais na rua pode matar") e o enunciador (Ministério do Transporte). Portanto, também precisamos trazer para esta análise um olhar sobre o projeto enunciativo da campanha - sua forma arquitetônica.

Com base nos contextos verbal e extra verbal já mencionados aqui, percebe-se 
que há no projeto enunciativo do Ministério dos Transportes uma busca por quebrar o estereótipo no qual as pessoas que provocam acidentes de trânsito são vistas como pessoas com imagens negativas (que sempre transgridem as regras de trânsito ao abusarem do excesso de velocidade, que fazem uso excessivo de álcool ao volante, que participam de rachas etc.). Ao trazer para o enunciado a imagem de uma pessoa de boa conduta, como as que resgatam animais abandonados, cria-se um contexto extra verbal relacionado a um horizonte de expectativas positivas - de pessoas com boas atitudes para com animais e sensíveis a causas humanitárias. Porém, esse horizonte extra verbal positivo é contraposto a um contexto verbal que remete a horizontes negativos - "Quem resgata animais na rua pode matar" e "Gente boa também mata".

Percebe-se, com isso, uma tentativa de o Ministério dos Transportes estabelecer uma interlocução com indivíduos que supostamente se consideram cidadãos comprometidos com boas práticas, e não com os indivíduos já rotulados como transgressores. Há, portanto, uma tentativa de "orientar a palavra do enunciador no horizonte de quem a interpreta" (BAKHTIN, 2015 p.56), estabelecendo relações dialógicas com elementos que fazem parte desses horizontes de pessoas de "boas práticas" na sociedade que, no caso da peça analisada neste artigo, seria o de estabelecer uma interlocução com simpatizantes de animais e protetores de causas animais, que se importam com animais abandonados nas ruas. Também faz parte do projeto enunciativo dessa campanha dar um recado a esses interlocutores, salientando para o fato de que ser um cidadão comprometido com boas práticas envolve mais do que adotar/cuidar de animais abandonados. No caso da campanha, envolve também levar em consideração atentar-se para o uso irresponsável do celular ao dirigir.

Sob uma perspectiva dialógica da linguagem, todo o projeto enunciativo é gerador de uma atividade responsiva, sendo o interlocutor não um mero receptor, mas um parceiro da produção de sentidos, um coenunciador. Portanto, o leitor desta campanha traz para essa relação que se estabelece com o enunciado (outdoor "Quem resgata animais na rua também mata", veiculado em paradas de ônibus) a sua entoação avaliativa e a sua responsabilidade ativa na negociação dos sentidos. Isso fica explicitado nas reações dos interlocutores à campanha. Nas palavras de Bakhtin, "a interpretação responsiva é uma força essencial que participa da formação do discurso, sendo ainda uma interpretação ativa, sentida pelo discurso como resistência ou apoio que o enriquecem" (BAKHTIN, 2015 p.54).

Os comentários a seguir ${ }^{4}$, postados em redes sociais em resposta à campanha "Gente boa também mata" e, em especial, à peça analisada por nós neste artigo, são exemplos de atividades responsivas e de interpretações ativas. No caso do recorte selecionado por nós, trazem para a discussão proposta aqui uma posição de não apoiar o discurso presente no projeto enunciativo da campanha, ressaltando um tom valorativo negativo, de indignação.

4 http://www.metropoles.com/brasil/transporte-br/campanha-do-ministerio-dos-transportes-gera-polemicanas-redes-sociais e https://noticias.uol.com.br/cotidiano/ultimas-noticias/2017/01/03/gente-boa-tambem-matacampanha-de-transito-gera-polemica-na-internet.htm 
Morta@ MeMatem

@ JuliaBobrow Parece que estão associando diretamente resgatar animais e matar pessoas, pegou bem mal. $\underline{6: 49 \text { PM - } 2 \text { Jan } 2017}$

Elika Takimoto @elikatakimoto

Tô ficando velha e implicante ou a campanha "Gente Boa Também Mata" é tão ruim q parece q autoriza a matar e faz chacota com as boas ações?

É a partir de postagens em redes sociais e de reportagens da mídia divulgadas após o lançamento da campanha que se torna possível discutir o lugar da produção de sentido do enunciado. No primeiro comentário "Parece que estão associando diretamente resgatar animais e matar pessoas, pegou bem mal", o autor explicita em sua resposta uma insatisfação com relação à peça analisada neste artigo. Percebe-se em sua interpretação um distanciamento do projeto enunciativo do Ministério ao não a entender como um alerta e, sim, como sendo um equívoco comparar indivíduos que resgatam animais na rua ao fato de matar pessoas. O tom trazido pelo verbo matar presente na frase "Quem resgata animais na rua pode matar", se analisado neste contexto específico da peça publicitária em questão, pode ser associado a algo criminoso, a uma ação criminosa. Porém, essa ação criminosa estaria diretamente ligada a uma prática social positiva: o resgate de animais de rua.

Na segunda postagem "Tô ficando velha e implicante ou a campanha 'Gente Boa Também Mata' é tão ruim q parece q autoriza a matar e faz chacota com as boas ações? ", o sentido presente nos enunciados utilizados na peça, somado ao tema que surge no contexto e nas condições de produção específicas, nos apontam para uma outra interpretação possível, na qual autoriza-se matar e diminui-se a importância de boas práticas sociais (como o resgate de animais abandonados). Nesse entendimento possível do enunciado, o contexto verbal (pode matar), dentro dessa situação específica, adquire em seu horizonte de valoração um tom permissivo. Ao fazer isso, relega às boas ações um tom menor. Nesse novo encontro do enunciado (peça publicitária da campanha Gente boa também mata, do Ministério dos Transportes, que consiste no outdoor "Quem regata animais na rua também pode matar", veiculado em paradas de ônibus) com a palavra do outro (postagem feita por esse leitor em específico), não há um coral de apoio para o discurso que o Ministério dos Transportes busca promover. Ou seja, percebe-se, a partir dos exemplos analisados acima, que houve uma não aceitação da peça publicitária por parte da maioria desses interlocutores.

Os memes que começaram a circular na internet após o lançamento da campanha Gente boa também mata são uma outra resposta ativa possível a esse enunciado. Neste artigo, selecionamos um meme que dialoga em específico com a peça publicitária outdoor "Quem resgata animais na rua também mata".

Fonte: http://adnews.com.br/internet/gente-boa-tambem-mata-ganha-memes-na-web.html 


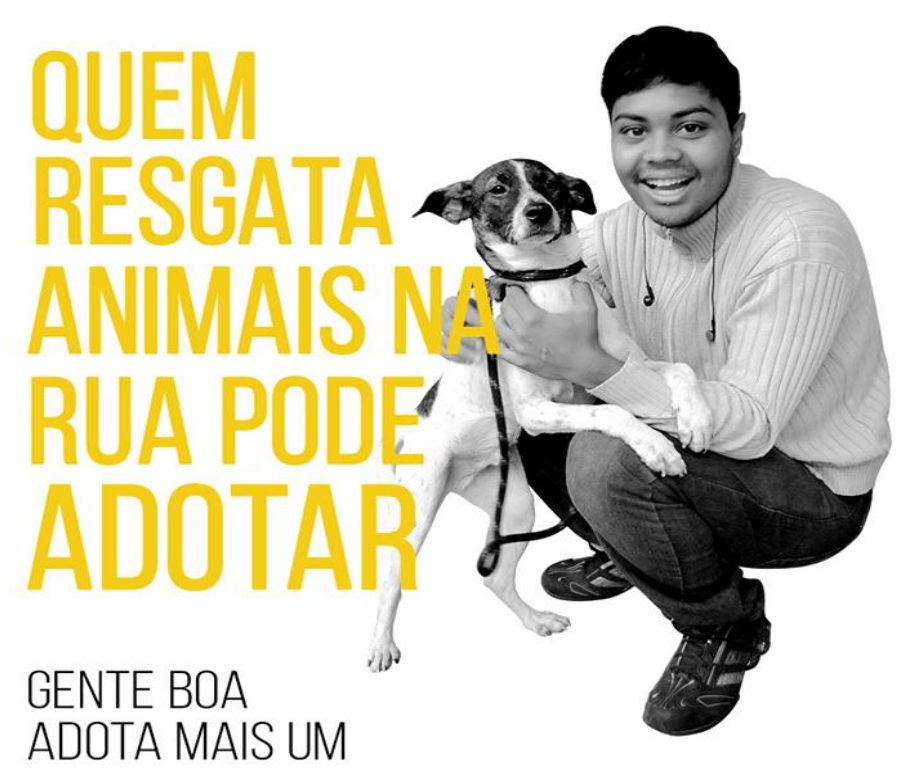

ADOTE NO CCZ

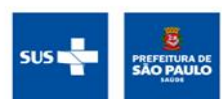

Figura 3- Campanha da Secretaria de Saúde de São Paulo

Nessa nova campanha, a Secretaria de Saúde da Prefeitura de São Paulo faz uma releitura da peça publicitária outdoor "Quem resgata animais na rua também mata" e, ao fazer isso, além de estabelecer um elo dialógico com a campanha proposta pelo Ministério dos Transportes, ao trazer uma construção composicional similar, também estabelece um outro diálogo com um novo público interlocutor (paulistanos que se interessam em adotar um animal abandonado), a partir de um novo propósito enunciativo que busca incentivar a adoção de animais.

Segundo Bakhtin (2011), ao enunciarmos, nos aliamos a alguns discursos e nos afastamos de outros. Ao escolher o gênero meme para se manifestar, a Secretaria de Saúde da Prefeitura de São Paulo, além de claramente se aliar ao discurso em defesa dos animais, marca sua posição de não apoio à peça publicitária outdoor "Quem resgata animais na rua pode matar", uma vez que o meme é um gênero que abarca em seu estilo uma proposta envolvendo humor e/ou sarcasmo. O enunciado "Quem resgata animais de rua pode adotar" dialoga com a campanha original do Ministério dos Transportes, satirizando-a, pois traz para a sua superfície o elo dialógico com a campanha anterior que tinha sido rejeitada pela maioria. Essas respostas ativas - como os memes - contribuem para que os sentidos e as valorações atribuídas à peça "Quem resgata animais de rua também pode matar" se consolidem; ou seja, as chances de a campanha publicitária do Ministério dos Transportes ser bem sucedida começam a diminuir cada vez que as respostas ativas (contrárias) são 
enunciadas e ganham repercussão na mídia ou na Internet.

Retomando alguns conceitos do Círculo, o discurso é uma soma de elementos que se dá entre um conteúdo (referindo-se a atos humanos); um material (constituído pela língua e pelos discursos verbais) e uma forma (modos de dizer e de organizar os discursos). Esse último, a forma, apresenta-se por meio composicional (materialidade do texto) e arquitetônico (envolvendo a organização do conteúdo expresso na matéria verbal e sua relação entre o enunciador, o tópico e o interlocutor).

\section{Considerações finais}

Conforme explicitado nos parágrafos anteriores, analisar um enunciado requer ter em conta um conjunto de elementos co-construídos na interação social, sempre de forma situada. $\mathrm{O}$ gênero discursivo é, pois, uma soma de todos esses elementos, que não farão sentido se os analisarmos em separado. Sob esse viés, o enunciado analisado por nós neste artigo (outdoor "Quem regata animais na rua também pode matar", veiculado em paradas de ônibus, que faz parte da campanha Gente boa também mata, do Ministério dos Transportes) reflete condições específicas que estão ligadas a um dado campo da atividade humana. Analisá-lo requer lidar de forma conjunta com o conteúdo temático, o estilo da linguagem presente nesse gênero discursivo e a sua construção composicional, assim como entender que a apreensão acerca de um dado enunciado se constrói na resposta do interlocutor, a partir de uma relação dialógica de uso da linguagem.

Nesse sentido, olhar para a polêmica que girou em torno da campanha Gente boa também mata sob a perspectiva bakhtiniana do discurso requer enfatizar as relações dialógicas que ocorrem no uso concreto da linguagem. Os sentidos e valores que são mobilizados dependem exclusivamente das condições das situações da comunicação em que ocorrem. Através da análise, foi possível refletir sobre como havia uma distância entre o projeto enunciativo da campanha e o seu resultado real; sobre como as respostas ativas sempre estão em elo dialógico com outros enunciados, no caso do meme analisado, estava em posição de distanciamento em relação ao enunciado anterior; sobre como as interpretações e valorações acerca de algo não são fortuitas, mas são resultado de fatores contextuais do uso da linguagem. Desse modo, os enunciados tocam em "milhares de linhas dialógicas vivas envoltas pela consciência socioideológica no entorno de um dado objeto da enunciação, não (podendo) deixar de ser participante ativo do diálogo social. " (Bakhtin, 1930-1936/ 2015, p. 49).

\section{REFERÊNCIAS}

BAKHTIN, Mikhail. Os gêneros do discurso. Tradução, prefácio, notas e glossário de Paulo Bezerra. São Paulo: Editora 34, 2016.

BAKHTIN, Mikhail. Palavra própria e palavra outra na sintaxe da enunciação. Organização aos cuidados de Valdemir Miotello. Pedro e João Editores 2011.

BAKHTIN, Mikhail. Teoria do Romance I. A estilística (1930-1936). Org. ed. russa Serjvei 
Botcharov e Vadim Kójmov. Tradução, prefácio, notas e glossário de Paulo Bezerra. São Paulo: Editora 34, 2015.

BERMÚDEZ, Ana. Campanha Gente boa também mata é alvo de críticas em redes sociais. Atualizado em 01 março 2018.Disponível em: https://noticias.uol.com.br/cotidiano/ultimasnoticias/gente-boa-tambem-mata-campanha-de-transito-gera-polemica-na-internet.htm. Acesso em 01 mar 2018.

MAIA, Maria. Conar: governo deve mudar campanha "Gente boa também mata". Atualizado em 01 mar 2018. Disponível em : http://veja.abril.com.br/entretenimento/conargoverno-deve-mudar-campanha-gente-boa-tambem-mata. Acesso em 01 mar 2018.

SOBRAL, Adail. Do dialogismo ao gênero. As bases do pensamento do círculo de Bakhtin. Mercado Letras, 2010.

VOLOSHINOV, Valentin. A Estrutura do enunciado. Tradução de Ana Vaz, para uso didático, com base na tradução francesa de Todorov, T. (La structure de l'énoncé), publicada em Mikhaïl Bakhtine. le principe dialogique, suivi de Ecrits du cercle de Bakhtine. Paris, Seuil, 1930/1981 